\title{
Exploring the physical controls of regional patterns of flow duration curves - Part 3: A catchment classification system based on regime curve indicators
}

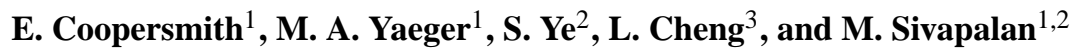 \\ ${ }^{1}$ Department of Civil and Environmental Engineering, University of Illinois at Urbana-Champaign, Urbana, IL, USA \\ ${ }^{2}$ Department of Geography, University of Illinois at Urbana-Champaign, Urbana, IL, USA \\ ${ }^{3}$ Water for a Healthy Country Flagship, CSIRO Land and Water, Canberra, ACT, Australia \\ Correspondence to: E. Coopersmith (ecooper2@illinois.edu)
}

Received: 9 May 2012 - Published in Hydrol. Earth Syst. Sci. Discuss.: 6 June 2012

Revised: 10 September 2012 - Accepted: 5 November 2012 - Published: 26 November 2012

\begin{abstract}
Predictions of hydrological responses in ungauged catchments can benefit from a classification scheme that can organize and pool together catchments that exhibit a level of hydrologic similarity, especially similarity in some key variable or signature of interest. Since catchments are complex systems with a level of self-organization arising from co-evolution of climate and landscape properties, including vegetation, there is much to be gained from developing a classification system based on a comparative study of a population of catchments across climatic and landscape gradients. The focus of this paper is on climate seasonality and seasonal runoff regime, as characterized by the ensemble mean of within-year variation of climate and runoff. The work on regime behavior is part of an overall study of the physical controls on regional patterns of flow duration curves (FDCs), motivated by the fact that regime behavior leaves a major imprint upon the shape of FDCs, especially the slope of the FDCs. As an exercise in comparative hydrology, the paper seeks to assess the regime behavior of 428 catchments from the MOPEX database simultaneously, classifying and regionalizing them into homogeneous or hydrologically similar groups. A decision tree is developed on the basis of a metric chosen to characterize similarity of regime behavior, using a variant of the Iterative Dichotomiser 3 (ID3) algorithm to form a classification tree and associated catchment classes. In this way, several classes of catchments are distinguished, in which the connection between the five catchments' regime behavior and climate and catchment properties becomes clearer. Only four similarity indices are entered
\end{abstract}

into the algorithm, all of which are obtained from smoothed daily regime curves of climatic variables and runoff. Results demonstrate that climate seasonality plays the most significant role in the classification of US catchments, with rainfall timing and climatic aridity index playing somewhat secondary roles in the organization of the catchments. In spite of the tremendous heterogeneity of climate, topography, and runoff behavior across the continental United States, 331 of the 428 catchments studied are seen to fall into only six dominant classes.

\section{Introduction}

This work is aimed at developing a catchment classification system that will help organize a large and diverse population of catchments within the continental United States into homogeneous groups on the basis of climate seasonality and runoff regime. The work is part of a broader study aimed at better understanding of the physical controls of the flow duration curve (FDC). It has been motivated by the observation that a catchment's regime curve (ensemble mean of the within-year variation of runoff) has a major impact on the shape of the FDC (Yokoo and Sivapalan, 2011), thus serving as the connective tissue between high and low flows that appear at the extreme ends of the FDC. This connection is formalized by developing a climatic classification system, based upon regime curves, that incorporates hydrologic information. 
Through numerical simulations with a physically based rainfall-runoff model applied to hypothetical catchments, Yokoo and Sivapalan (2011) showed that the FDC of total runoff can be partitioned into two components: the FDC of the surface (or fast) flow and that of subsurface (or slow) flow. This result has been further confirmed by the comprehensive analysis of the FDCs of some 200 catchments located within the continental United States by Cheng et al. (2012). Yokoo and Sivapalan (2011) further argued that while both the fast and slow flow components are driven by different climate and landscape properties, the FDC of the slow, subsurface flow component closely resembles and could be more easily reproduced from the catchment's regime curve. If this is true, then spatial variations of the regime curve, and associated climatic and landscape controls that result from their interactions, could help explain the regional patterns of the FDCs within the continental United States. So while understanding of the process controls of the regime behavior is important in its own right, it is also valuable for understanding the controls of the FDC.

Catchments everywhere are highly variable, displaying enormous complexity, with a large number of degrees of freedom, which makes it very difficult to make general statements about their responses. Yet, despite substantial heterogeneity and the complexity of their responses exhibited by observations, experience with modeling studies and predictions indicates that, at the catchment scale, simple models with a small number of parameters can describe the majority of catchment responses (Sivapalan et al., 2003). This has encouraged hydrologists to organize and classify catchments into homogeneous or similar groups on the basis of a small number of explanatory variables, as a vehicle towards generating improved understanding and predictions (Dooge, 1986; Blöschl and Sivapalan, 1995; McDonnell and Woods, 2004; Olden et al., 2011). Due to the self-organization of climatic and landscape features arising from their co-evolution, and their impact on multi-scale process interactions and feedbacks, any catchment classification system must be necessarily holistic.

One of the pivotal differences between our work and its predecessors is the scope of our classification attempts. For instance, a finely detailed study by Mosley (1981) classified hydrologic responses in 175 small catchments in New Zealand, resulting in narrowly defined characteristics and finely split classes. Ogunkoya (1988) classified 15 catchments in Nigeria, but considered lithographic details and other features that may be less appropriate if a classification scheme is to be broadly applied and minimalist in its information requirements, as is the objective of this work. Burn (1997) applied seasonality metrics to help understand flood frequencies in 59 prairie catchments in central/western Canada chosen specifically because they experience comparable climates, and thus all present hydrologic regimes driven by flood events from spring snowmelt. Their results, while useful, do not address the tremendous climatic diversity that can occur at the continental scale. Recognizing this, Burn and Goel (2000) chose a more diverse assortment of catchments in India, using a $k$-means technique to effectively extract groups of similar catchments. While these catchments exhibited more geographic complexity than the previously discussed studies, this location is still somewhat hydrologically limited. In addition, clustering algorithms of this kind present groups that are similar without specifying the physical drivers that contribute to such similarity - an imperative for deeper understanding of process controls.

Rather than simply examine how quantitative characteristics of catchments in various regions are optimally organized, this analysis also focuses upon why these catchments present the observed climatic and hydrologic characteristics that they do. As mentioned earlier, to understand the physical controls on the FDC, one can classify runoff regimes using empirical runoff regime data, as seen in Haines et al. (1988), where clusters of catchments with similar flow regimes were obtained by minimizing within-group variance of clusters of monthly streamflows. While this procedure does yield qualitative explanations, they were generated after the fact, rather than as part of the analysis itself. Qualitative insights are strongest as the result of objective, rather than reflective analysis. One way of gaining qualitative insights from an objective process is the use of hydrologic signatures. Wagener et al. (2007) proposed a classification system that is based on similarity of key signatures of catchment runoff response, including, with decreasing timescale, inter-annual variability, regime curve (i.e., mean within-year variability of runoff), and the flow duration curve (FDC). Taking this idea further, Sawicz et al. (2011) classified catchments located in the eastern half of the United States, using several catchment-based signatures including the runoff ratio, the slope of a flow duration curve, and other streamflow properties. This was followed by a comparative study of several catchments based on detailed physically based modeling that can account for differences in topography, soil types, geomorphology, and vegetation (Carillo et al., 2011). These studies began investigating the physical underpinnings of the groups that emerge from classification - we intend to continue in a similar vein, using simple regime-curve-based features.

With respect to hydrologic, signature-based classification, there has been considerable success in developing similarity measures and catchment classification on the basis of mean annual runoff, expressed in terms of the Budyko curve and the aridity index (Budyko, 1974; Zhang et al., 2001). The focus on the regime curve in this paper is a natural extension to establish the basis for similarity of catchment responses. Whereas the competition between water available and energy available governs similarity at the annual timescale, the shape of the regime curve is governed additionally by the relative timing of precipitation and potential evaporation, and the ability of the landscape to store and release water.

Frameworks for climate classification were first applied broadly via the Köppen-Geiger system - identifying similar 
climates using basic information on the variability of precipitation and temperature (Köppen, 1936), and later updated by Peel et al. (2007). The classification of regime behavior presented in this paper can be seen as a precursor to a possible hydrological extension of the Köppen-Geiger system towards classification of catchment responses. The KöppenGeiger system is based on the number of months in which average precipitation or average temperature exceeds a given threshold. However, by excluding hydrology from the system, it fails to distinguish certain catchments that display different filtering behaviors. Consider that Köppen-Geiger classifies the entire southeastern United States identically. Understanding the distinctions in rainfall/runoff timing allows for more nuanced analysis of the FDC - this was the hypothesis raised by Yokoo and Sivapalan (2011) upon which this paper builds.

This paper is the third of a four-part series whose aim is to better understand the physical drivers of observed regional patterns of the FDCs. The first paper, by Cheng et al. (2012), focuses directly on the FDC and approaches the problem empirically, while the second (Ye et al., 2012) adopts a top-down modeling approach to explore the process controls of the regime curve and their subsequent relationship to the FDC. The final paper (Yaeger et al., 2012) synthesizes the insights from the different perspectives of the first three papers. The present paper begins with a discussion of hydrologic similarity, specifically that of regime behavior. Four key indices that will be used to quantify hydrologic similarity and the reasons for their selection are then presented in Sect. 2. This is followed in Sect. 3 by details of the methodology used to construct the decision tree. Section 4 presents the results of the implementation of the decision tree, while the robustness of the classification tree is verified in Sect. 5. The paper concludes with a hydrologic assessment of the catchment classification achieved, including lessons learned and questions left for future work.

\section{Similarity of regime behavior}

Since the focus of this paper is on catchment regime behavior, two catchments will be considered hydrologically similar if their regime behavior can be deemed similar. In this paper, four key similarity indices will be used to characterize the similarity of regime behavior, and are defined and discussed in detail later in this section. These include (i) aridity index, a measure of aridity that, to first order, determines the annual water balance, (ii) a seasonality index that quantifies the strength of seasonal variability of precipitation within the year, (iii) the timing (mean date) of precipitation peak within the year, and (iv) the timing (mean date) of runoff peak within the year. Since the climate of the continental United States is such that the seasonal variation of energy (and temperature) is relatively uniform across the country, the timing of precipitation is effectively a measure of the phase difference between the seasonality of precipitation and potential evaporation. On the other hand, the timing of the runoff peak (especially in relation to precipitation and potential evaporation) captures the mechanisms of storage (in soil water or snow storage) and release (in terms of subsurface drainage or snowmelt). In this sense the similarity indices provide a first-order mapping towards the regional variations in dominant processes highlighted in the parallel study of Ye et al. (2012).

\subsection{An example of regime behavior}

Figure 1 presents the daily regime curves of precipitation, potential evaporation, and total runoff for a MidwesternAmerican catchment, located in Kansas. The left image (Fig. 1a) is obtained, using MOPEX daily data from 1948 to 2001 (Sivapalan et al., 2011; Cheng et al., 2012) ${ }^{1}$, using ensemble averaging by calendar day. While Fig. 1a does provide useful information about the within-year (daily) variability of the chosen variables, for the purpose of catchment classification in this paper, a sliding, 30-day moving average is generated, as shown in Fig. 1b. Equation (1) captures this smoothing:

$P_{i}=\frac{\sum_{i-15}^{i+15} P_{i}}{\sum_{i-15}^{i+15}}$

where $P_{i}$ represents the average precipitation for day $i$ of the year; as a point of clarification, this calculation is circular. Many hydrological analyses (Köppen, 1936; Haines et al., 1988, and others) deploy monthly regime data to depict seasonal patterns of rainfall and runoff. A 30-day moving average achieves this idea of a 30-day window without creating arbitrary monthly boundaries. In classifying catchments on the basis of the daily regime curves of climatic and runoff data, in this paper we will focus upon images like this one (Fig. 1b) for all 428 catchments within the MOPEX database (Duan et al., 2006). The proposed classification scheme will be built around four key indices, each extracted from the smoothed regime curves of the type presented in Fig. 1b.

\subsection{Similarity indices used}

In the spirit of Köppen-Geiger, a key objective of this research is the classification of regime behavior using an absolute minimum quantity of data, on the basis of four very simple and widely available similarity indices. To estimate these four indicators, three daily time series are required: precipitation, potential evaporation, and total runoff. The first index is the aridity index $\left(E_{\mathrm{p}} / P\right)$, the ratio of annual potential evaporation to annual precipitation; it measures the competition

\footnotetext{
${ }^{1}$ MOPEX data obtained from http://voda.hwr.arizona.edu/ mopex/.
} 

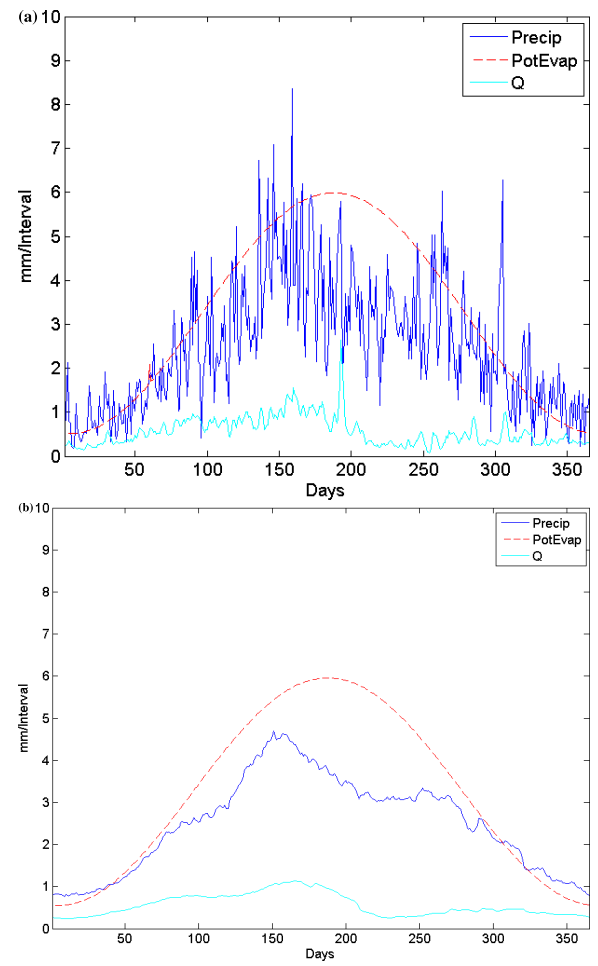

Fig. 1. (a) Daily regime curve, and (b) 30-day moving average, Marais des Cygnes River, near Ottawa, Kansas, USA.

between energy available and water available, and is seen as a good first-order indicator of runoff ratio (ratio of annual runoff to annual precipitation). Note that the phase of $E_{\mathrm{p}} / P$ is not addressed because, within the continental US, every catchment's $E_{\mathrm{p}}$ curve peaks within a couple of weeks during the summer, and $E_{\mathrm{p}}$ is very low during winter months; thus the curve's amplitude is subsumed by the value $E_{\mathrm{p}} / P$. The seasonality index and maximum day of precipitation are both estimated from the daily precipitation time series. The seasonality index measures the strength of within-year (seasonal) variability of precipitation, and is zero if the precipitation is uniform throughout the year. The timing of rainfall peaks is a reflection of the phase difference between the timing of the precipitation peak and that of potential evaporation (Milly, 1994), given that, in the continental United States, the timing of potential evaporation's peak is uniform spatially. Finally, the timing of maximum runoff accounts for the response of the catchment to the interactions between precipitation and potential evaporation. The timing of runoff allows for differences in storage and release processes between different regions, owing to distinctions in topography, snowfall, snow storage and melt processes, and also differences in the physiological responses of vegetation. The decisions with respect to the four indices are justified in terms of understanding the interplay between wetting and drying, and the timing separating rainfall from runoff, as discussed in Cheng et al and Ye et al. (2012). Within the United States, any three indices are insufficient to understand the nuanced behavior of the catchments we examined, but the addition of a fourth (at least for the vast majority of MOPEX catchments) resolves the discrepancies.

In essence, the four indices represent answers to the following four questions:

- "Is this catchment very humid, somewhat humid, temperate, somewhat arid, or very arid?"

_ "Is rainfall relatively consistent year-round, somewhat seasonally dependent, or highly seasonally dependent?"

- "When, during the year, is rainfall greatest?"

- "When, during the year, is streamflow greatest?"

Other variables, such as runoff ratio $(Q / P)$ were considered, but ultimately not adopted because they were correlated with other variables $\left(E_{\mathrm{p}} / P\right)$ and failed to improve the quality of classification. Our classification system was reconstructed after the omission of each of the four features to verify that, in fact, all four features are necessary. Further justification of the four features selected is available within the Supplement.

With respect to the independence of the four features, seasonality and aridity index are almost entirely independent $\left(r^{2} \sim 0.14\right)$. Seasonality and date of max precipitation are fully independent $\left(r^{2}<0.01\right)$. Seasonality and date of max runoff are almost entirely independent $\left(r^{2} \sim 0.14\right)$. Aridity index and date of max precipitation are independent $\left(r^{2} \sim\right.$ $0.05)$. The same is true for aridity index and date of max runoff $\left(r^{2} \sim 0.06\right)$. Though one might suspect the date of peak precipitation and peak runoff to be related, the $\mathrm{r}^{2}$-value connecting the date of maximum precipitation and the date of maximum runoff is only 0.21 . Though there are clusters where the maximum runoff follows the maximum rainfall by a few days or weeks, there are also numerous catchments with virtually constant annual rainfall, yet still characterized by a defined runoff peak. Finally, there are catchments that receive their highest rates of precipitation during fall/winter, then store that water in snowpacks, yielding peak runoff in April, May, or June.

While there are other features that are relevant in understanding the behavior of a given catchment (proportion of precipitation as snow, etc.), these concepts are included, at least in large part, in the four features chosen. While these four features are sufficient for our purposes, future research may consider adding further indicators to improve specification within certain regions.

\subsubsection{Aridity index: dry or wet?}

Figure 1 shows that, in this catchment in Kansas, the daily potential evaporation rate is almost uniformly in excess of the daily precipitation rate throughout the year. The aridity index $\left(E_{\mathrm{p}} / P\right)$ is estimated by summing the mean daily rates of potential evaporation (PE) over the 365-day time series and dividing it by the sum of the mean daily precipitation 
rates over the same 365-day period. The aridity index thus measures the competition between energy available and water available annually: $E_{\mathrm{p}} / P>1$ for arid (dry) catchments whereas $E_{\mathrm{p}} / P<1$ for humid (wet) catchments.

Figure 2 presents regional patterns of the aridity index for 428 catchments belonging to the MOPEX database. It shows that eastern catchments tend to be largely humid (except in the south), whereas Midwestern catchments tend to be mostly semi-arid, becoming more arid as they approach the Rocky Mountains and the desert south-west, and becoming humid again in the Pacific Northwest. Essentially one finds systematic east-west (and north-south) trends in the aridity index, contradicted by some outliers in the south-east and north-west.

\subsubsection{Seasonality index: is precipitation uniform or periodic?}

Figure 1 presented a catchment whose precipitation and also runoff response exhibited significant seasonality, with rainfall being much higher during the summer than during winter months. This is a feature exhibited by a significant number of catchments belonging to the MOPEX database. Potential evaporation is also highly seasonal, although in this case there is very little phase difference between precipitation and potential evaporation. The relative magnitudes of precipitation and potential evaporation are likely to have an impact on runoff regime, and must be accounted for in the classification scheme. Walsh and Lawler (1981) defined a seasonality index for precipitation on the basis of average monthly rainfall values, which in essence is a measure of within-year variance. In this paper we use an adaptation of Walsh and Lawler to accommodate the 365 -day smoothed precipitation regime curve as follows:

$$
\frac{\sum_{i=1}^{365}\left|P_{i}-\frac{\sum_{i=1}^{365} P_{i}}{365}\right|}{\sum_{i=1}^{365} P_{i}}
$$

where $P_{i}$ represents the value obtained from Eq. (1) The seasonality index helps to distinguish those regions in which precipitation is highly variable seasonally from those in which rainfall is comparatively uniform throughout the year.

Figure 3 presents the spatial distribution of the estimated seasonality index across the USA. In the eastern part of the country, precipitation is fairly uniform year-round with the exception of three catchments located in southern Florida. Moving westward, the seasonality index tends to increase displaying moderate seasonality in the Midwest (midcontinent) and peaking in those catchments near the Pacific. While there are a few catchments that do not follow this trend in the northern Rocky Mountains, the general trend remains consistent.

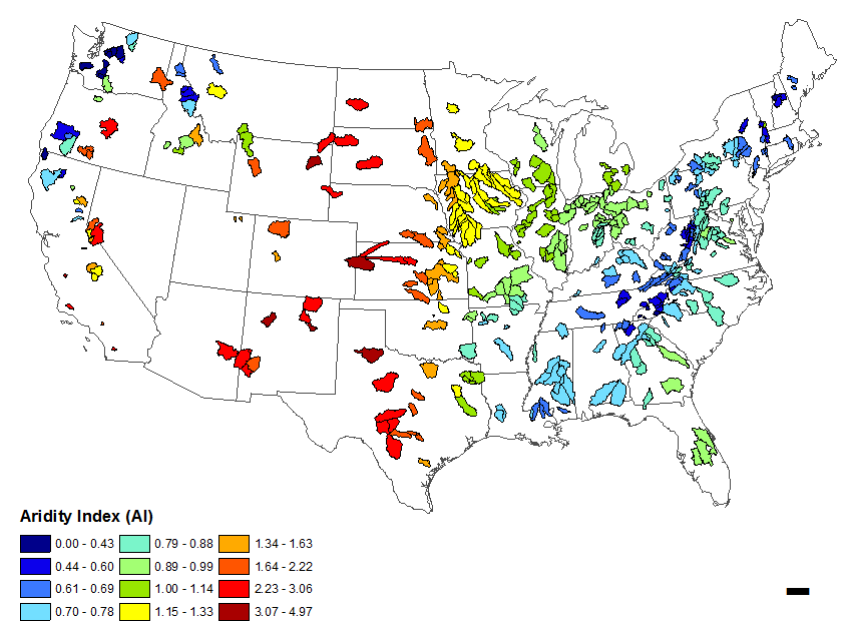

Fig. 2. Spatial distribution of the aridity index $\left(E_{\mathrm{p}} / P\right)$.

\subsubsection{Day of peak precipitation: in-phase or out-of-phase with respect to PE?}

With the seasonality index defining the strength of seasonal variability of precipitation, another key feature is the timing of the maximum precipitation within the year. In this case, the metric we use is the date (from 1 to 365) on which the smoothed precipitation regime curve has its peak. Given that the timing of the peak of potential evaporation is uniform throughout continental United States, the timing of the precipitation peak serves to focus attention to the phase difference between these climate variables, i.e., whether precipitation seasonality is in phase with that of potential evaporation (e.g., precipitation peaks during June or July), is out-of-phase (precipitation peaks during December or January), leading PE somewhat (precipitation peaks during spring months) or lagging PE somewhat (precipitation peaks during fall months). As a side note, it is important that this similarity index be estimated from a regime curve obtained with a suitably long moving window to avoid mischaracterizing a catchment. These distinctions are important, since the phase differences between the seasonality of water input and energy input impact storage and release mechanisms, and can thus impact the magnitude and timing of runoff as well.

Figure 4 presents the distribution of the day of maximum precipitation using a circular color coding; i.e., if the day of maximum precipitation happens to fall on 31 December for a catchment, then the similarity index is quite similar to another catchment with its precipitation peak falling on 2 January, even though the timing index will be " 365 " for the first catchment and "2" for the second catchment. Although numerical values are different, they are actually similar with respect to the timing of the precipitation peak. The color coding reflects this similarity.

In this case, the east-to-west trends seen in the case of aridity index and seasonality index no longer hold. Although the 


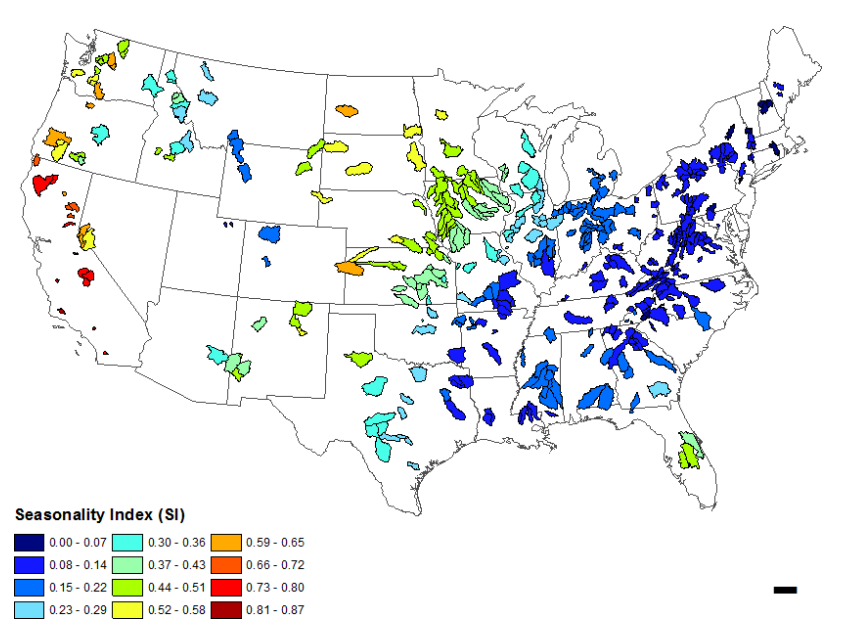

Fig. 3. Spatial distribution of the seasonality index.

Midwestern regions see precipitation peak in the late spring to early summer, there is much more variability across the continent, creating smaller clusters that are less defined by longitude and latitude alone. The southern Appalachians are quite different from their northern, snowy counterparts; the Pacific coast displays a notable gradient north to south, and several catchments in the monsoon-influenced southwest distinguish themselves from their snowmelt-driven neighbors to the north, and their hurricane-influenced neighbors to the east.

\subsubsection{Day of peak runoff: role of catchment storage and release processes}

Analogous to the day of peak precipitation, the day of peak runoff $(1-365)$ is the final piece to the classification puzzle. In this case, the differences between the catchments reflect not only the magnitude and phase differences between precipitation and potential evaporation, but also the transformations that happen at the land surface (storage and release processes, including below-ground soil and groundwater processes and above-ground snow storage and snowmelt), as illustrated by Milly (1994).

The results are presented in Fig. 5, once again using a color coding scheme that is circular (1-365). As with the day of peak precipitation, we observe clusters that are not solely longitude- or latitude-driven, including considerable local variations that may reflect landscape heterogeneity. The Pacific Northwest distinguishes itself due to the out-of-phase relationship between precipitation (peaks during winter) and potential evaporation (peaks during summer). In the Midwest and along the east coast, there is considerable heterogeneity, and in some cases even adjacent catchments show differences in runoff timing. Along the Appalachian Mountains in the eastern half of the continent, runoff peaks appear in early spring, presumably driven by melting snow and spring rainfall.

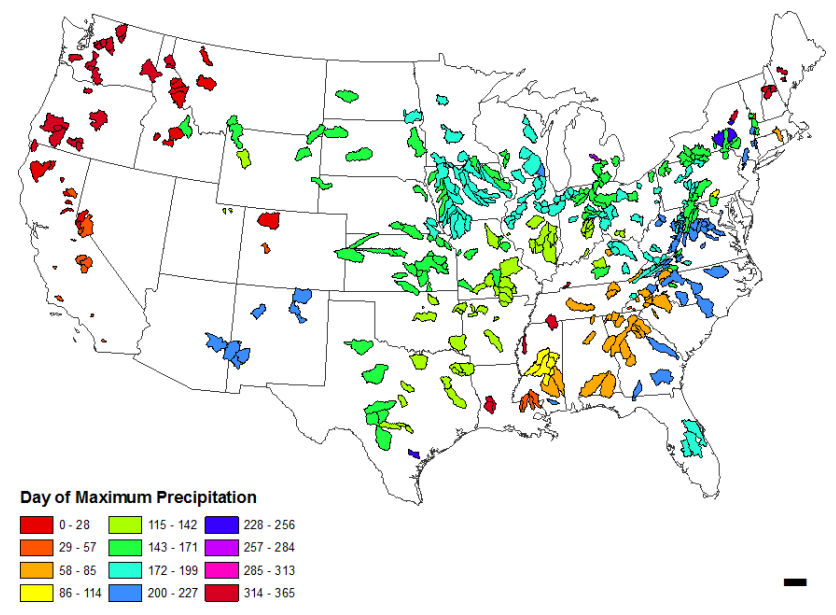

Fig. 4. Spatial patterns of the day of peak precipitation day (1-365).

\section{Developing a catchment classification system: decision trees, similarity metrics, and clustering algorithms}

\subsection{Decision trees for grouping catchments}

The goal of this section is to describe the methodology adopted in this paper to "group" catchments exhibiting similar regime behavior, and separate them from those that are different. Figures 2 through 5 also exhibited certain regional trends across the continental USA with respect to each of the four similarity indices we had considered, and some level of clustering. In the same way, if the regime curves of the type presented in Fig. 1, generated for each of the 428 catchments in the MOPEX database, are superimposed upon a large map of the USA, one could see regional trends, including the emergence of distinct clusters of similar regime behaviors (at least qualitatively). Is there a connection or possible mapping between the former and the latter? Our hypothesis in this paper is that a combination of the 4 similarity indices governs the regime behavior and can be the basis of their classification.

Considering that ultimately we want to develop a catchment classification system on the basis of regime behavior, and the fact that we have 4 different similarity indices that might collectively determine similarity of regime behavior, how can we develop a robust classification system? One way to develop such a classification system is via "decision trees" that can recursively divide the 428 catchments into self-similar groups in such a way that, at each step in the decision tree, the variability of a catchment attribute within each group is less than the variability between groups. The reason for a classification tree rather than another clustering algorithm, of which there are several in the literature (neural networks, nearest-neighbor algorithms, genetic algorithms, etc.), was that this structure allows for qualitative insights to emerge along the way rather than a black box that 


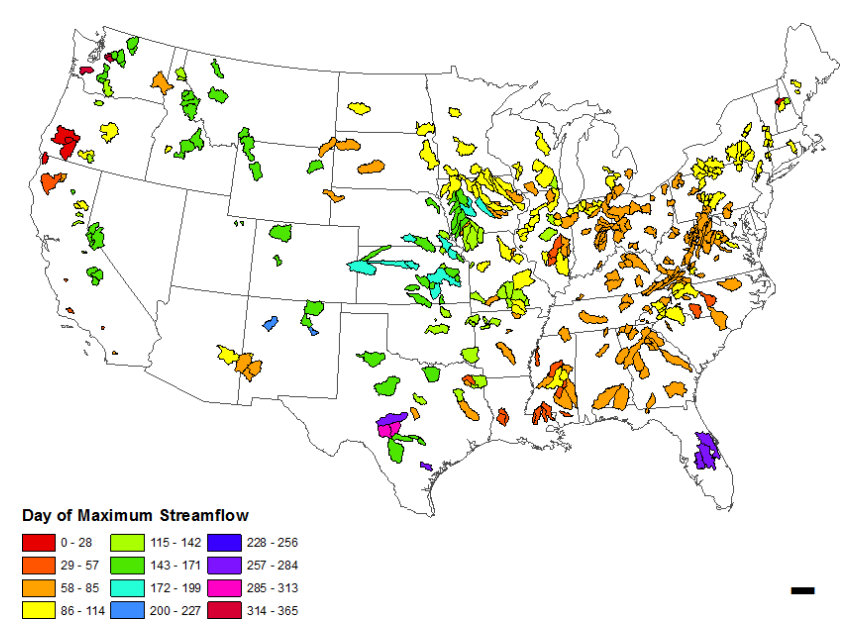

Fig. 5. Day of peak runoff (1-365).

delivers groups without explanation. With this method, as "observers" of the algorithm, we can see what splits occur on what values at what point in the process, allowing us to ask the following: What is the most important, most distinguishing characteristic for all US catchments? What if we only consider the non-seasonal half? Constructing such trees requires a suitable metric - a mathematical definition of similarity (of regime behavior) that can be deployed for any group of catchments - a metric that encompasses the four key indices.

\subsection{Metric of regime similarity}

Each of the four similarity indices, seasonality index $(S)$, the aridity index $(A)$, day of peak precipitation $\left(\tau_{p}\right)$ and maximum runoff day $\left(\tau_{q}\right)$, shows considerable variability across the catchments, which can be expressed in terms of a variance measure. For $S$ this is straightforward, with the estimation of the standard deviation obtained from

$\sigma_{S}=\sqrt{\frac{\sum_{i=1}^{n}\left(S_{i}-\mu_{S}\right)^{2}}{n-1}}$

where $S_{i}$ is the seasonality index for catchment $i, \mu_{S}$ is the its mean over all catchments, and $n=428$ is the number of catchments. An analogous estimate can be obtained for the standard deviation of the aridity index, $\sigma_{A}$.

In contrast, for $\tau_{p}$ and $\tau_{q}$, this estimation is not as straightforward. This is due to the circularity of the timing of the two peaks (i.e., 1-365), as in the case of four catchments whose values for $\tau_{p}$ are $361,364,359$, and 3 . To overcome this, we transform $\tau_{p}$ and $\tau_{q}$ into new variables $C_{1}$ and $C_{2}$, both of which naturally fall between -1 and +1 , and overcome the circularity problem.

$C_{1}=\sin \left(\frac{\tau_{p}}{365} \cdot 2 \pi\right), C_{2}=\cos \left(\frac{\tau_{p}}{365} \cdot 2 \pi\right)$
By estimating $\sigma_{C_{1}}$ and $\sigma_{C_{2}}$, the standard deviations of $C_{1}$, and $C_{2}$, respectively, we can then estimate the standard deviation of $\tau_{p}, \sigma_{\tau_{P}}$, as follows:

$\sigma_{\tau_{P}}=\sqrt{\sigma_{C_{1}}^{2}+\sigma_{C_{2}}^{2}}$.

The standard deviation of $\tau_{q}$, expressed as $\sigma_{\tau_{Q}}$, can be estimated in an analogous manner.

In summary, for the four similarity indices outlined, their between-catchment variabilities across the entire MOPEX database of 428 catchments are characterized by $\sigma_{S}, \sigma_{A}, \sigma_{\tau_{P}}$, and $\sigma_{\tau_{Q}}$ respectively. To ensure that no one index overwhelms the others by virtue of its numerical scales, the variance of each index, whether it contains all 428 catchments or a smaller subset of them, is normalized by the four constants listed above. For any group of $m$ catchments, we define a new quantity, $E$, the metric of regime similarity associated with that group, as follows:

$E=\sqrt{\left(\frac{\sigma_{S, m}}{\sigma_{S}}\right)^{2}+\left(\frac{\sigma_{A, m}}{\sigma_{A}}\right)^{2}+\left(\frac{\sigma_{\tau_{P}, m}}{\sigma_{\tau_{P}}}\right)^{2}+\left(\frac{\sigma_{\tau_{q}, m}}{\sigma_{\tau_{q}}}\right)^{2}}$

Essentially, the regime similarity metric, $E$, is a representative measure of the combined within-group variance of the four similarity indices for any group of $m$ catchments, with equal weights attached to each of the similarity indices.

\subsection{Clustering algorithm: Iterative Dichotomiser 3 algorithm (ID3)}

Classification trees offer a straightforward approach for grouping objects on the basis of similarity or variance measures (Breiman et al., 1984). Such tools are routinely included in many statistical programming packages (Breiman et al., 1993). The clustering or grouping algorithm used in this paper is the Iterative Dichotomiser 3 (ID3) algorithm developed by Quinlan (1986), which was re-coded as part of this research. This algorithm has found classification applications in forest resource management (Aertsen et al., 2011), crop identification for soil management (Pena-Barragan et al., 2011), mapping of arid rangeland vegetation (Brodley and Freidl, 1997; Lailiberte et al., 2007), and prediction of the failure of business ventures ( $\mathrm{Li}$ et al., 2010).

The algorithm's implementation is explained next. Given all 428 catchments, choose a value of any one of the four indices (e.g., seasonality index) with which to partition all catchments. This will yield two clusters - those with a statistic (i.e., seasonality index) above that value and those with a statistic below that value. Iterate over four possible similarity indices to choose the value of one of these indices that minimizes the regime similarity metric, $E$, and weighted by the number of constituents in each subsequent class (as explained next). Repeat recursively until either value of $E$ can no longer decrease significantly or these clusters become too small. The first split, atop the decision tree, is offered in detail in the following paragraphs. 
By definition, the normalized value of the variance of the entire distribution of any independent variable is equal to unity. Substituting into Eq. (6) to obtain the value of $E$ of the initial data belonging to 428 catchments yields

$E=\sqrt{(1)^{2}+(1)^{2}+(1)^{2}+(1)^{2}}=\sqrt{4}=2$.

When all 428 catchments were assessed, although each of the four similarity indices was considered, the best-performing splitting criterion turned out to be a seasonality index of 0.2564 . There are 266 catchments with seasonality index values less than 0.2564 and 162 with seasonality indices that exceed 0.2564 . The new value of the regime similarity index, $E$, is now calculated as follows:

$E^{\prime}=266\left(E_{S \leq 0.2564}\right)+162\left(E_{S>0.2564}\right)$.

In this case, $E_{S \leq 0.2564}$ denotes the regime similarity metric of the set of catchments, for which $S \leq 0.2564$ (266 in all) and $E_{S>0 . \ldots 2564}$ represents the similarity metric of the set of catchments for which $S>0.2564$ (162 in all). In each term of Eq. (8), Eq. (6) is now used to estimate $E$ for only the subgroups of 266 and 162 respectively. Substituting into Eq. (8) this gives, after the first split,

$E^{\prime}=[266(1.1838)+162(2.1992)] / 428=1.5681$.

This represents the minimum possible value of $E$ after one single split. Thus what began with an E-value of 2 has now improved to 1.5681. It is worth noting that one branch, the one with more seasonal catchments, actually displays greater "disorder" than the entire dataset. However, given that 266 of the 428 catchments begin to cluster significantly (i.e., $E=$ 1.1838), the small increase in the disorder of the remaining 162 is justified.

At this point, the algorithm as described above can be repeated recursively, locating an optimal split criterion at each node by choosing from one of the four similarity indices, thus branching outward down the tree. Splitting ceases when it is determined that the catchments within a given terminal node are maximally similar - no further splitting will decrease the regime similarity metric significantly, or there is only a single catchment left at that node (and thus $E$ is zero). In some cases, there are very few catchments left in a given node to be split with an obvious pair of clusters. In such cases, adopting different splitting criteria might yield the same two groups. In these rare cases, a manual choice of splitting is invoked to choose the most appropriate class delineator.

\section{Results: what patterns emerge, and where are the largest clusters?}

We now present the results of the application of the clustering algorithm presented above, describing the breakdown developing at each level of the decision tree. For presentation purposes, depending on the magnitudes of the similarity indices at which the splits occur, we divide each similarity index into several (3 to 5) distinct and meaningful classes. The combination of these classes then produces the nomenclature we need to describe the catchment classes at each level.

\subsection{Nomenclature for catchment classes}

The nomenclature we have adopted is letter-based, using up to five letters of the alphabet to characterize the range of values of each of the four similarity indices; these are presented below.

\subsubsection{Codes for aridity index}

- $V=$ "Very Humid", $E_{\mathrm{p}} / P<\sim 0.5$;

- $H=$ "Humid", $\sim 0.5<E_{\mathrm{p}} / P<\sim 0.75$;

- $T$ = "Temperate", $\sim 0.75<E_{\mathrm{p}} / P<\sim 1.2$;

- $S=$ "Somewhat Arid", $\sim 1.2<E_{\mathrm{p}} / P<\sim 2$;

- $A=$ "Arid", $\sim 2<E_{\mathrm{p}} / P$.

\subsubsection{Codes for seasonality index}

- $L=$ "Low Seasonality", $S<\sim 0.25$;

- $I=$ "Intermediate Seasonality", $\sim 0.25<S<\sim 0.5$;

- $X=$ "eXtreme Seasonality", $\sim 0.5<S$.

\subsubsection{Codes for day of precipitation peak}

- $J$ = "June", max rainfall occurs in early or mid-summer (not necessarily in June);

- $W=$ "Winter", max rainfall occurs in winter (midFebruary or March);

- $B=$ "Blizzard", max rainfall in late November to midFebruary;

- $P=$ "Printemps", max rainfall during spring.

\subsubsection{Codes for day of runoff peak}

- $Q=$ max runoff during summer months, early June through August;

- $F=$ "Fall/hurricane season", generally in September/October, uncommon (TX \& FL);

- $M=$ "Melt", spring melt usually at a peak in April, May, or early June;

- $C=$ "Cold runoff", max runoff occurring from early February to before April;

- $D=$ "December", max runoff during December/January or early February. 


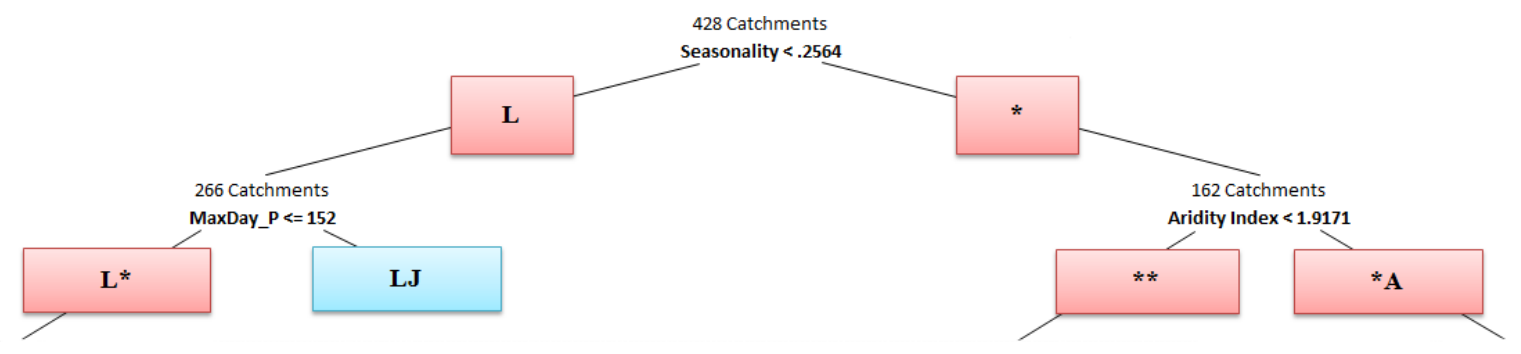

Fig. 6. The top two layers of the classification tree (terminal node shown in blue).

The classes described above can theoretically describe $3 \times 5 \times 4 \times 5=300$ different combinations of the similarity indices (and associated catchment groupings), although, as will become apparent soon, an overwhelming majority of those combinations will never occur. The nomenclature for these classes was developed after seeing the clusters that emerged. For instance, with respect to the aridity index, there were a few classes where $E_{\mathrm{p}} / P$ was much lower than 0.5 , some classes with $E_{\mathrm{p}} / P$ greater than 2.5 , and three notable groupings in between. For this reason, five classes were selected. However, with respect to seasonality, in examining groups it became evident that there were catchments with very little seasonality, catchments with extremely high rates of seasonality, and intermediate catchments. Thus, three were chosen. The intention had been to generate as few classes as possible. Indeed we will show that the first six most dominant classes will encompass 331 of the 428 catchments.

\subsection{Initial split: top of the classification tree}

The classification tree begins with the complete database of 428 MOPEX catchments. As mentioned before, the population of 428 catchments is split recursively into smaller, more homogeneous groups, being named along the way depending on the value(s) of the similarity indices at play at each split. After the very first split, the dataset is divided into two large clusters, which are not terminal nodes, but rather are intermediate nodes, and these are further split into four clusters, and so on. After each split, the resulting pair of clusters begins to receive a more detailed code using the letters above, depending on the value of the similarity index that is in play at each split.

Seasonality turned out to be the single most important factor in creating order in the 428 catchments in the MOPEX database at the first level. Two clusters emerged: one characterized by catchments with a low seasonality index (L) and the other characterized by catchments with a "not low" seasonality index. This is shown in Fig. 6, with the left branch labeled " $L$ " and the right branch labeled "**" because it could be either an "I" or an "X" type of seasonality. The transfer of the first level split onto a map of the United States makes the classes resulting from the first split easy to understand hydrologically, as seen in Fig. 7.
The results presented in Fig. 7 indicate that the seasonality index, after only one binary split, effectively partitions the continental United States geographically in a meaningful way. In the eastern part of the country, rainfall is relatively uniform throughout the year, from New England in the northeast, down the Appalachian Mountains to the Ozarks, stretching into the Midwest. Only three eastern catchments in this database, those in Florida, deviate from this pattern, as they see large amounts of rainfall during a warm, humid, hurricane-influenced summer/fall and considerably less during the winter. In the western United States, excluding a handful of catchments in the northern Rocky Mountains, every catchment displays considerable seasonal variability of precipitation, from the Midwestern catchments characterized by a precipitation that is in phase with potential evaporation to the Pacific coast catchments in which the precipitation regime is out-of-phase with respect to that of potential evaporation.

The second split criterion, for the lower seasonality, eastern catchments (colored blue in Fig. 7), is the timing (day) of precipitation peak while for the more seasonal, western catchments, the split criterion becomes the aridity index (see Fig. 3). For less seasonal catchments, the dividing date falls on 1 June; for the more seasonal catchments, the dividing aridity index is roughly 1.9. This leads to four classes, as shown in Fig. 6, one of which (LJ) is a terminal node. The transfer of these four clusters, after two consecutive splits of the original dataset, onto the map of the United States is presented in Fig. 8. The results presented in Fig. 8 show an east-west division based on the seasonality index at the first level; a northeast-southwest split occurs in the eastern (nonseasonal) region via the timing of rainfall, while in the west a split based on aridity index distinguishes the Pacific Northwest and the northern Midwest catchments from the remaining western catchments.

\subsection{Four quadrants of the classification tree}

The four main clusters of similar climatic regions obtained in the second level will be further split by the recursive algorithm outlined above until smaller, very similar climate clusters remain. The details of this are not presented here for reasons of brevity; only the resulting final classification tree is 


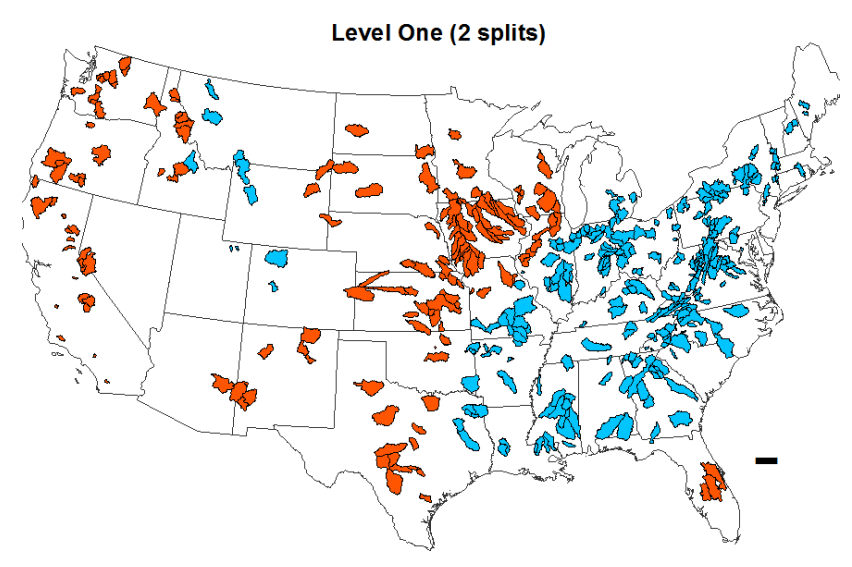

Fig. 7. First split, low seasonality (blue) and higher seasonality (orange).

presented. Even here, because of the size of the resulting tree, it is most easily viewed in portions, which we call quadrants, relating to the major clusters formed at the end of the level two splits. In what follows, each quadrant of the classification tree is presented and discussed in detail.

\subsubsection{First quadrant: low seasonality, max precipitation before 1 June}

Figure 9 presents the expansion of the first quadrant. Six climate regions describe the 119 catchments that comprise this group. The most populous group, "LWC" contains 52 catchments, 50 of which are located in the southeastern states. While this terminal grouping has been obtained without the use of the aridity index, using only seasonality and the timings of precipitation and runoff, the 52 catchments all display $E_{\mathrm{p}} / P<0.87$, displaying a tight cluster of humid catchments where rainfall and runoff peak in February or March. The second-most populated group is "LPC", containing 29 catchments from the eastern Midwest. Once again, although the aridity index has not been used as a split criterion to obtain this cluster, the 29 catchments have similar $\mathrm{E}_{\mathrm{p}} / \mathrm{P}$-values, near or slightly below one. This class is distinguished from LWC by virtue of maximum rainfall occurring later in the spring. A third, well-populated cluster is found in 28 "LPM" catchments located in the southeastern regions of the Midwest where rainfall and runoff both peak during springtime. The "LBMH" catchment in Montana, which seems unusual for its geography given its low seasonality, and humidity $\left(E_{\mathrm{p}} / P \sim 0.67\right), 3$ "LBMS" catchments from Colorado and Montana, which are similar to the LBMH oddity, only considerably drier $\left(1.17<E_{\mathrm{p}} / P<1.66\right)$, and 6 "LPQ" catchments, also from the mountain west (Wyoming) where rainfall peaks in the spring instead of the winter, round out this quadrant.

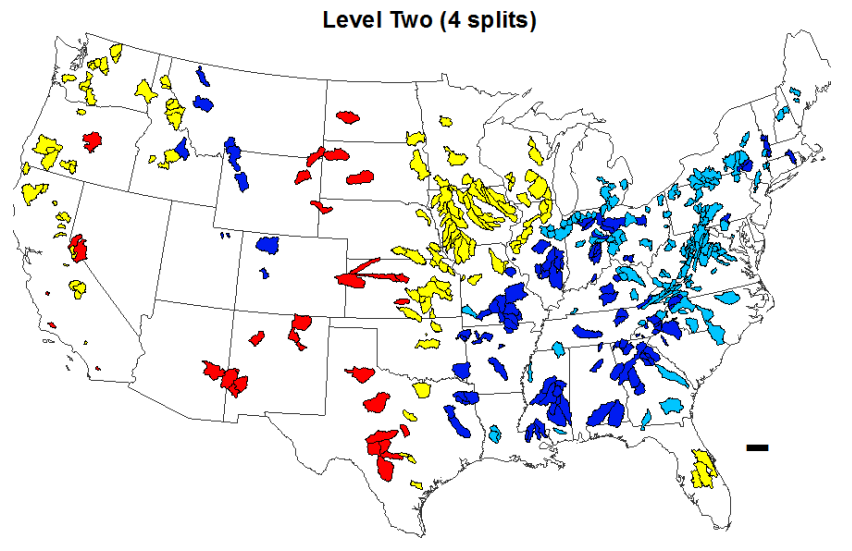

Fig. 8. Second split: low seasonality and earlier precipitation peak (dark blue), low seasonality and later precipitation peak (light blue), higher seasonality and non-arid (yellow), higher seasonality and arid (red).

\subsubsection{Second quadrant: low seasonality, max precipitation after 1 June}

This quadrant becomes fully organized with only two criteria for splitting, leaving 147 catchments which all carry the "LJ" designation. Although the maximum date on which runoff occurs is not used to create this class, 145 of the 147 catchments observe maximum runoff between mid-February and late April (the remaining two peaks occur in the first week of May). In fact, 124 of the 147 catchments peak between the second week of March and the first week of April. Furthermore, although once again the aridity index is not used to generate this cluster, all 65 catchments fall between $E_{\mathrm{p}} / P \sim 0.5$ and $E_{\mathrm{p}} / P \sim 1.05$. This class of catchments defines the mid-Atlantic and Appalachian regions of the United States, extending into the eastern Midwest. This quadrant of the tree, albeit expressed as a single node, is illustrated in Fig. 10.

\subsubsection{Third quadrant: higher seasonality, non-arid}

This quadrant of the tree is the most diverse by a considerable margin. The criteria for this quadrant are, to reiterate, the seasonality index $>0.2564$ and an aridity index $\left(E_{\mathrm{p}} / P\right)$ below 1.9. Some 128 catchments meet these conditions and are further segmented into 12 terminal nodes as shown in Fig. 11 (note that two terminal nodes classify to the common Midwestern climate of "ITC"). However, despite the apparent complexity, two climates describe 75 of the 128 catchments. The first, and most common, "ISQJ" contains 39 catchments in the Midwest and southern Midwest. The second most common, ITC is quite similar to the previous grouping geographically, although it is more humid and maximum runoff arrives sooner. This class contains 36 catchments from the Midwest and northern Midwest. The remaining clusters, partitioning the Pacific Northwest, consist of 6 humid catchments from 


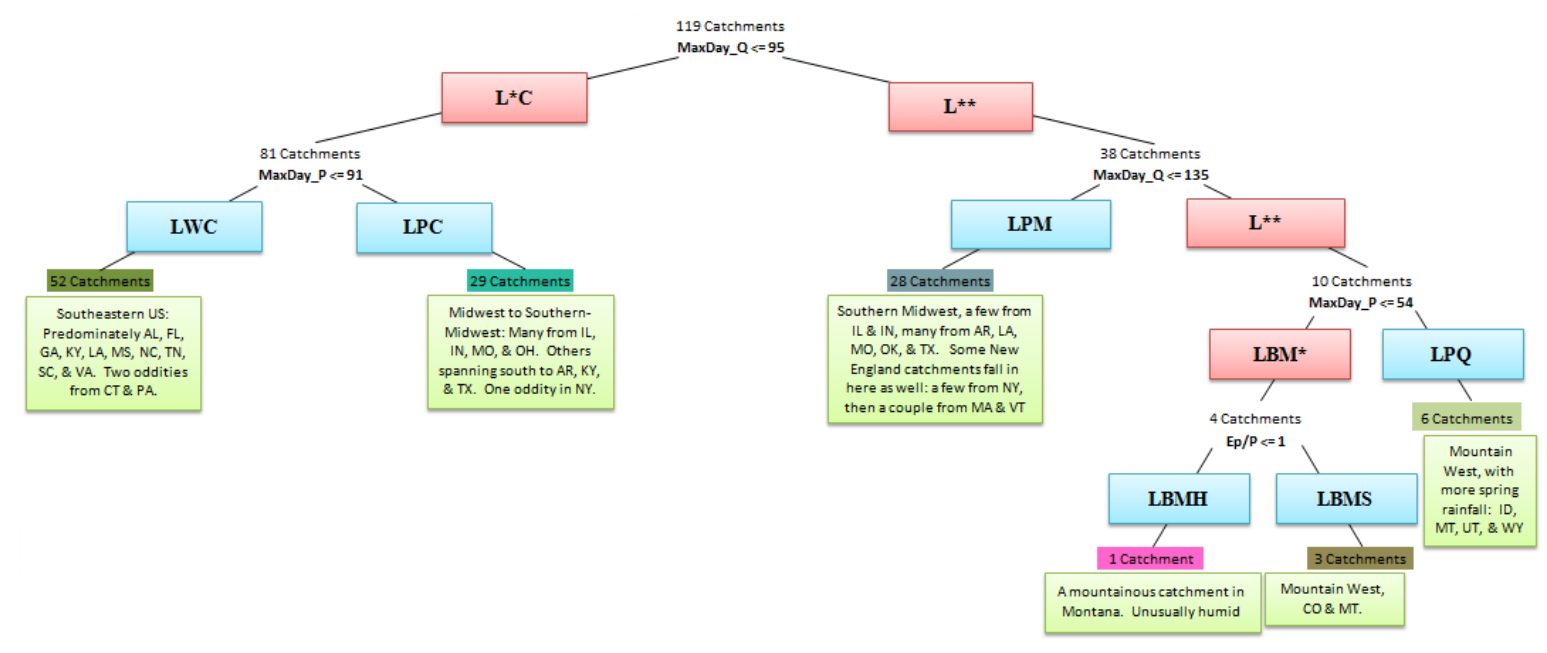

Fig. 9. Low seasonality, early precipitation peak: expanded (terminal nodes in blue).

northern California and Oregon ("XHD”), 7 catchments in Idaho ("IHM"), 6 extremely humid catchments in Washington ("XVM"), 10 more temperate catchments in the Pacific Northwest from Washington, ("XTM"), 3 extremely humid catchments in Washington ("IVD"), which differ from their XVM counterparts by virtue of their lower seasonality index, and winter runoff peak, 3 Floridian catchments ("ITF"), which are truly unlike any others in the United States, 7 drier Midwestern catchments with early runoff peaks ("ISCJ"), 2 drier Pacific northwestern catchments ("ISCB"), and 3 drier southern Californian catchments ("XSC"), and 6 drier southern Californian/Nevadan catchments with later runoff peaks ("XSMB").

The terminal nodes in the third quadrant contain 10 or fewer catchments, describing certain niche climates of United States. These mini-clusters often describe several catchments that are very similar to each other, but quite different from their neighbors.

\subsubsection{Fourth quadrant: higher seasonality, arid}

In this final quadrant, the 34 remaining catchments are further divided into five terminal nodes. The most common classification ("IAQ") contains 16 catchments, a miscellaneous assortment of the country's most arid locations, including 10 from the southwest, 5 from the Midwest, and one remarkably arid catchment in Wyoming (the mountain west). The remaining clusters consist of three Californian catchments that represent the driest American Pacific climates ("XADB"), the northern Midwestern "badlands", six extremely arid catchments in Nebraska and North and South Dakota ("XACJ"), a cluster of seven arid southwestern catchments, one oddity in the Pacific Northwest, ("IACJ"), shielded from the Pacific coast by the Cascade Mountains, and three arid catchments in Texas characterized by runoff peaks occurring as late as the fourth week of October ("IAF"). Figure 12 presents the final quadrant.

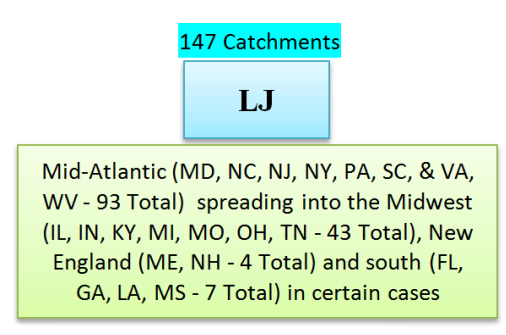

Fig. 10. Low seasonality, late precipitation peak: expanded (terminal node).

\subsection{Summary of the resulting catchment classification and the largest six classes}

In total, the classification tree yielded 24 terminal nodes, depicting 24 distinct classes according to the criteria we have used. The geographic representation of these 24 classes on a map of the continental United States is presented in Fig. 13, revealing distinct regional associations of many of the major catchment classes.

However, of the 428 catchments which comprise the MOPEX dataset, 331 can be described by only six climate classes: LWC, LPC, LPM, LJ, ITC, and ISQJ. There are only two other groupings that contain 10 or more catchments. While admittedly this could be due in part to the makeup of the MOPEX dataset, which contains more catchments in certain regions than in others, it still suggests that while 300 different classifications are theoretically possible using the coding system adopted here, over $77 \%$ of the catchments are well described by $2 \%$ of the possible classes, and the entire dataset is captured by $8 \%$ of all possible classes. In terms of the overall variance of the full dataset, the following are the within-group variances for the six most common classes: LWC - 26.9\%, LPC - 23.9\%, LPM - 29.8\%, LJ - $43.3 \%$ (with $140+$ catchments), ITC - $28.1 \%$, ISQJ - 


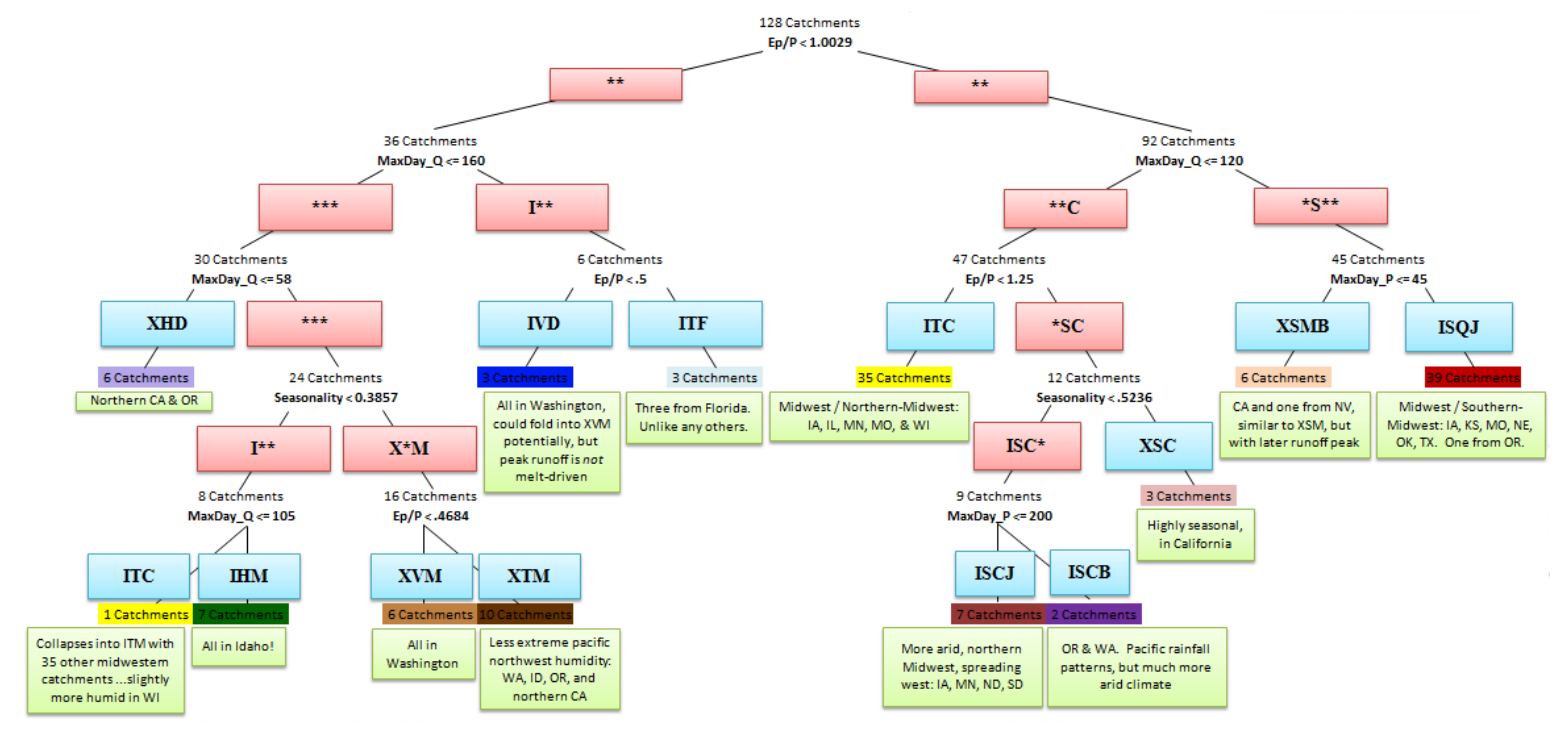

Fig. 11. Higher seasonality, non-arid: expanded (terminal nodes in blue).

$46.5 \%$. Considering that these groups comprise $77 \%$ of the database, this is quite encouraging, as these clusters contain much less than half of the variance of the original dataset using very simple indices.

Three of the largest six classes are found within the first quadrant (LWC, LPC, and LPM). The catchments belonging to these three classes are characterized by limited seasonality, and are essentially catchments with pre-spring maximum rainfall and runoff (LWC), catchments with pre-spring peak runoff, but mid-spring maximum rainfall (LPC) and catchments with springtime rainfall and runoff peaks (LPM). The entire set of catchments in the second quadrant (belonging to the terminal LJ class) is clearly the fourth member of the largest six classes. These catchments display limited seasonality, humid climates, peak runoff during the springtime (likely melt-driven from the Appalachian mountain range), and peak rainfall during the summertime. The final two members of the largest six are found in the third quadrant: ISQJ and ITC (and none of the classes in the fourth quadrant falls within the largest six). The two Midwestern classes, ISQJ and ITC, both contain catchments with rainfall that is in phase with potential evaporation. However, the ISQJ catchments are notably more arid, with $E_{\mathrm{p}} / P$ averaging roughly 1.5 , as opposed to an average of roughly 1 for ITC. As a result of the more temperate climate, the ITC group displays peak runoff during early spring, when stored water from winter has thawed. On the other hand, ISQJ, characterized by drier soils, shows its runoff peak in late May or June, at the same time as its precipitation peak.

\subsection{Robustness of classification: recurrent, dominant clusters}

When classification systems are generated using recursive, splitting algorithms (those that minimize variance at each stage without concern for future splits), there is a tendency to over-fit one's data. Although variance is minimized at every stage, ensuring that we do not split a group of catchments without purpose, caution is required to prevent fitting the noise inherent in the dataset rather than true patterns. To this end, the same algorithm was applied to a 197-catchment subset of the larger, 428-catchment dataset. These 197 catchments were chosen due to their comparatively richer datasets (fewer missing days, more complete years, etc.) and form the dataset that has been employed by Ye et al. (2012), Cheng et al. (2012), and Yaeger et al. (2012) in the accompanying papers that are all focused on exploring the physical controls of the FDCs from different perspectives.

Although naturally there are subtle differences in the tree that is formed in the latter case, the important features of the tree remain unchanged (not presented for reason of brevity). Using the notion of quadrants, as described in the previous section, the first quadrant is not only characterized by lower seasonality and peak rainfall before 1 June (the same date as the 428-catchment tree), but also contains six total terminal nodes as well. Furthermore, the three most common classes from that quadrant of the 428-catchment tree and their number of constituents (LWC - 52, LPC - 29, and LPM - 28) are mirrored in the most common classes in the 197-catchment tree as well (LWC - 21, LPC - 11, and LPMT - 7). The additional letter $\mathrm{T}$ from the subset tree is the result of slightly different sequences of the splitting, yielding essentially the same groups. 


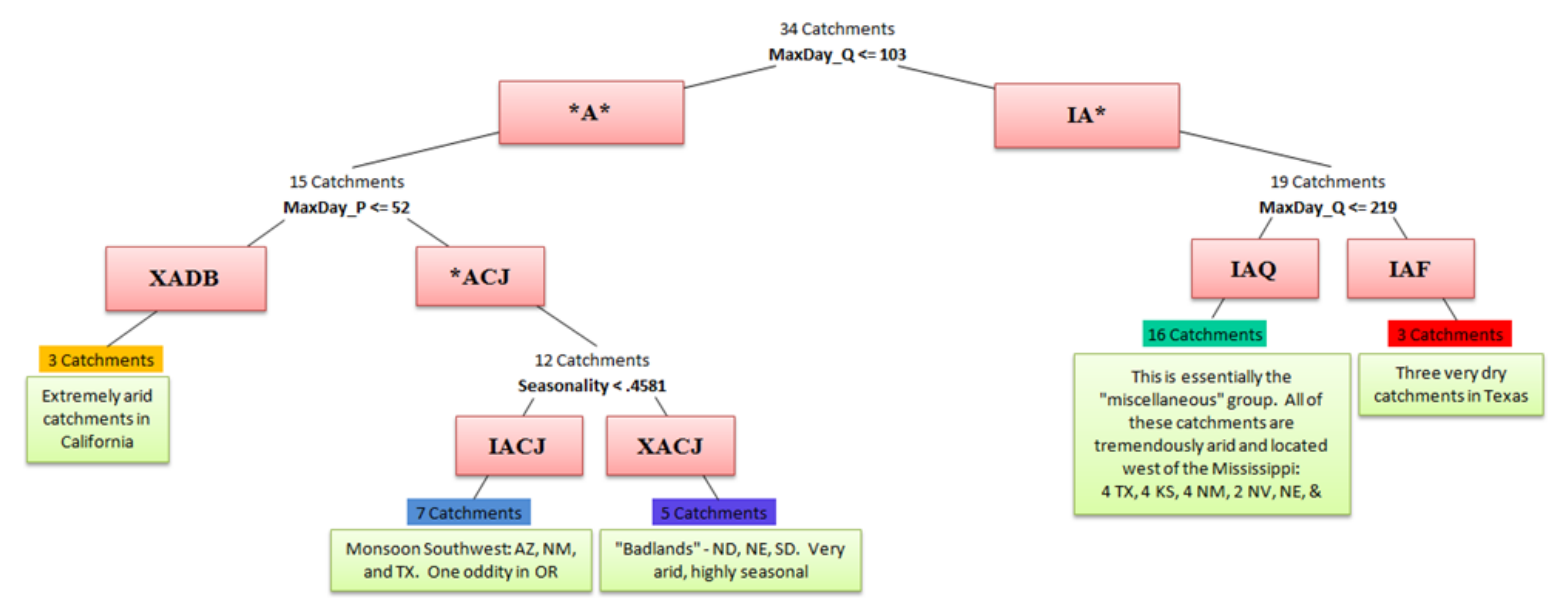

Fig. 12. Higher seasonality, arid: expanded (terminal nodes in blue).

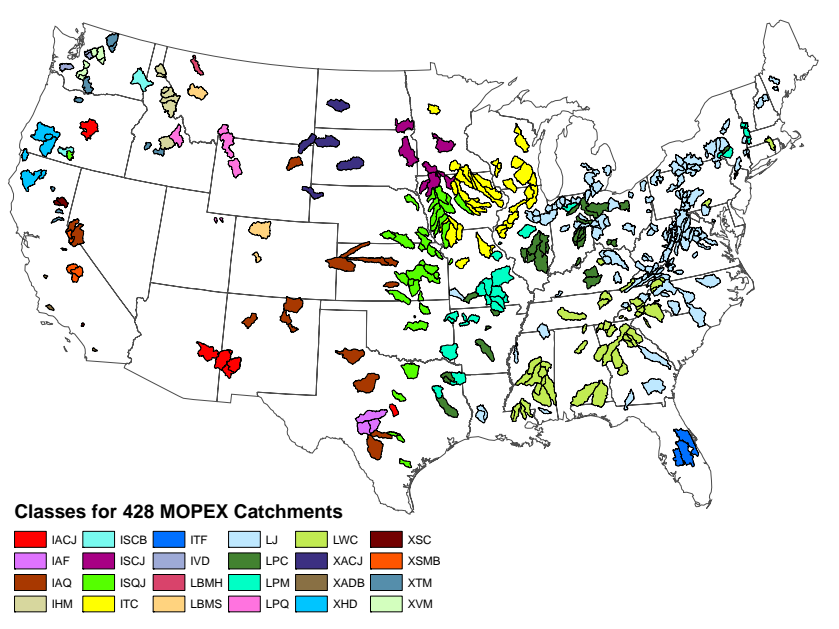

Fig. 13. All classes.

The second quadrant of the 197-catchment tree, like the 428-catchment tree, contains the single class LJ, now composed of 65 catchments rather than 147. The remaining two quadrants also show some differences, this likely resulting from the nature of the dataset. Unfortunately, given the challenges associated with data gathering in more arid catchments, many of the catchments characterized by substantial missing data are found in the nation's more arid locations. As a result, the 428-catchment tree contains a much higher proportion of arid catchments (thus, the second split criterion for more seasonal catchments is $\left.E_{\mathrm{p}} / P\right)$. Conversely, the 197catchment tree contains a smaller proportion of arid catchments and, thus, splits on the maximum day of precipitation to define its third and fourth quadrants. Despite this, the two most common classes on this side of the 428-catchment tree (ISQJ - 39 and ITC - 36) still find their parallels in the 197catchment tree (ISQJ - 15 and "IJTC" - 20). The remaining, less common groups do display some overlap, although in this case differences appear simply because certain groups

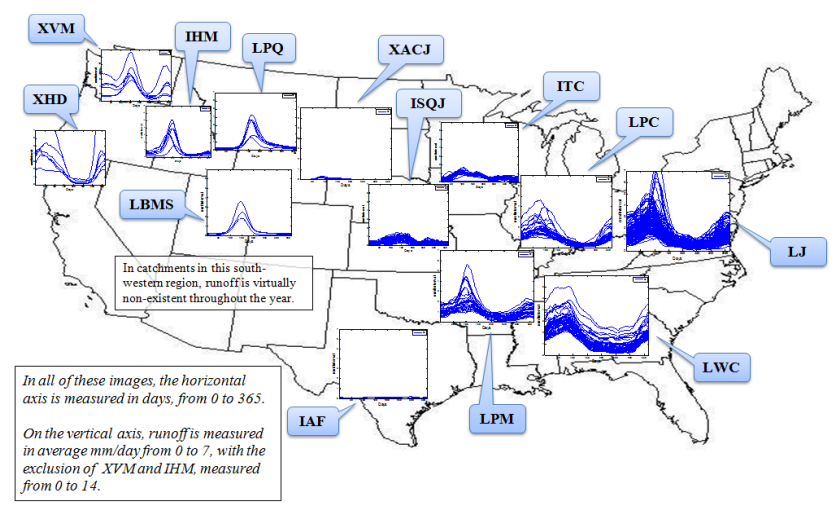

Fig. 14. Clusters of runoff regimes.

are not represented at all in the 197-catchment subset, or find themselves folded into other classes. Despite these minor distinctions, once again, the nearly identical largest six classes again define over $70 \%$ of all catchments and the tree's general structure remains intact. This demonstrates that not only is the classification system intuitively satisfying in its simplicity, but is robust to alterations in the dataset.

The most effective argument for the success of this classification system lies in its ability to validate the initial hypothesis - that simple climatic regime indicators lead to clusters of similar runoff behavior. Each cluster of runoff regimes is presented in Fig. 14, demonstrating regional self-similarity. While certain clusters with larger numbers of catchments (notably LJ) do display some variance among their constituents, the overall pattern of runoff timing associated with each catchment still remains intact. Moreover, analysis of the flow duration curves by class confirms our initial speculation, as these flow duration curves are organized by a classification tree constructed solely with regime curve features. Table 1 quantifies the decrease in variance with respect to 100 key percentiles of the FDC as one progresses down the 
Table 1. Decreasing FDC variance (layer-by-layer down the tree).

\begin{tabular}{rr}
\hline Level 0 & $100 \%$ \\
Level 1 & $86 \%$ \\
Level 2 & $68 \%$ \\
Level 3 & $63 \%$ \\
Level 4 & $54 \%$ \\
Level 5 & $47 \%$ \\
Level 6 & $47 \%$ \\
Level 7 & $46 \%$ \\
\hline
\end{tabular}

classification tree. In other words, not only are the four key indices being grouped effectively, but the FDCs of the constituent groups are well-organized as well. More detailed discussions of this connection and its relationship to other findings from the first two papers of this series can be found in Yaeger et al. (2012).

\section{Conclusions}

This paper has presented the application of a clustering algorithm (i.e., Iterative Dichotomiser 3, or ID3 algorithm) for classifying catchments across the continental United States with respect to their climatic seasonality and regime behavior (i.e., mean within-year variation of runoff). The classification was achieved by assessing the catchments in terms of a metric of regime similarity, $E$, which is a composite measure estimated on the basis of the magnitudes of four similarity indices: (i) a seasonality index of precipitation, (ii) aridity index, (iii) timing of maximum precipitation, and (iv) timing of maximum runoff. The clustering algorithm was applied to 428 catchments across the continental United States belonging to the MOPEX dataset.

The clustering algorithm identified 24 distinct classes. Even though the classification was achieved with just four numbers from each catchment (similarity indices), and only the max date of the runoff regime curve was used, the regime behavior for each of the classes showed distinct differences between classes and strong similarity within. This confirms the power of the simple classification scheme for predicting regime behavior across the continental United States, subject to the limitations of the geographical extent of the dataset and coverage across the country. Considering that three of the four indices used to construct the classification tree are based upon climate, it comes as no surprise that climate's impact is readily apparent. Just as Köppen-Geiger delineated the nation into clusters of climatic similarity a century ago, climate still dominates the hydrologic landscape, creating distinct, hydrologically similar clusters.

The resulting classes also display strong regional associations and patterns, which is very valuable to further explore the climatic and landscape controls underlying the resulting catchment classes. Whether the final group is IHM, with seven catchments all located in the state of Idaho, or ITF, with three catchments all located in Florida, or IAF, with three catchments located in one region of Texas, these groups are not only numerically similar, but geographically contiguous as well in many cases.

Despite the enormous heterogeneity of catchments represented in the MOPEX dataset, just six classes accounted for over $77 \%$ of the catchments. The classification system is found to be robust, producing the same recurring six clusters even with a smaller subset of the full dataset. Each of the recurring, dominant six classes displays distinct characteristics that suggest their own set of hydrologic drivers. In the Midwest, the aridity index determines whether runoff is driven by the spring thaw of water frozen in soil storage (ITC) or by the arrival of summer rains (ISQJ). In the south-east, runoff timing in late winter (LWC and LPC) or early spring is governed by the temperatures in and around the Appalachian Mountains. In the north-east, spring runoff is likely the result of melting of snow (LJ). In the area in which the southeastern United States merges with the Midwest, seasonality begins to appear strongly, and runoff is driven by springtime rainfall (LPM). In addition to these largest six clusters, other smaller, niche climates display distinct behaviors. From the monsoondriven southwest (XACJ), where precipitation occurs mainly in a narrow band of summer months, to the extremely humid Pacific Northwest, where runoff peaks are driven by extreme winter rainfall (IVD) or the melting of snowcaps in the spring (XVM), the United States exhibits a tremendously heterogeneous group of catchments.

The analyses presented in this paper have identified catchment groupings that are similar in terms of their runoff regime. What makes them similar? Their regime curves certainly suggest as much, but does that imply similar dominant processes? The accompanying paper by Ye et al. (2012) explores their regime behavior from a process perspective, by adopting a top-down modeling approach. Is there a recognizable mapping between the catchment classification found in this paper and the classification of dominant processes highlighted in Ye et al. (2012)? Furthermore, this paper has been motivated by our quest to explore the physical controls of the flow duration curve (FDC), considering that the regime curve provides a major connective tissue between the high flow and low flow ends of the FDC. Cheng et al. (2012) presented an empirical analysis of the regional patterns of FDCs across the continental United States and their physical controls. Is there a connection between the regional groupings of catchments based on the regime curve and regional patterns of variation of the FDCs? The accompanying synthesis paper by Yaeger et al. (2012) addresses these questions through cross comparisons between the results of each of these three studies to draw general conclusions about the physical and process controls of the regime curve and the flow duration curve, helping to discover not only which catchments are similar, but also why they are similar. 
Finally, it is important to acknowledge the limitations inherent in the classification system presented. Although the continental United States represents a diverse and rich array of climate conditions and landscape features, it is natural that it does not contain every conceivable combination of climate and landscapes. It may very well be the case that such climates exist on other continents. It is to be hoped that future efforts will integrate global climate data into an enhanced tree, duplicating this work on a larger, multi-national scale. Secondly, while the classification system classified 428 gauged catchments (including information on runoff timing) into distinct classes, without a further effort to incorporate catchment or landscape features that impact runoff generation, especially runoff timing, application to ungauged catchments is not feasible. This calls for further research that will overcome this major limitation of this study.

\section{Supplementary material related to this article is available online at: http://www.hydrol-earth-syst-sci.net/ 16/4467/2012/hess-16-4467-2012-supplement.pdf.}

\begin{abstract}
Acknowledgements. The work presented in this paper was carried out as part of the NSF-funded project "Water Cycle Dynamics in a Changing Environment: Advancing Hydrologic Science through Synthesis" (NSF grant EAR-0636043, M. Sivapalan, PI), and also the NSF project "Understanding the Hydrologic Implications of Landscape Structure and Climate - Toward a Unifying Framework of Watershed Similarity" (NSF Grant EAR-0635998, T. Wagener, PI). Special thanks are owed to Matej Durcik of SAHRA (University of Arizona) for providing the version of the MOPEX dataset used in this study. We would like to thank Ross Woods and the other reviewers for their constructive criticism and insight - the paper is unquestionably stronger as a result.
\end{abstract}

Edited by: P. Claps

\section{References}

Aertsen, W., Kint, V., Van Orshoven, J., and Muys, B.: Evaluation of modeling techniques for forest site productivity prediction in contrasting ecoregions using stochastic multi-criteria acceptability analysis (SMAA), Env. Modell. Softw., 26, 929-937, 2011.

Blöschl, G. and Sivapalan, M.: Scale issue in hydrological modeling - a review, Hydrol. Process., 9, 251-290, 1995.

Breiman, L., Friedman, J., Olshen, R., and Stone, C.: Classification and Regression Trees, Wadsworth International Group, Belmont, CA, 1984.

Breiman, L., Friedman, J., Olshen, R., and Stone, C.: Classification and Regression Trees, Chapman and Hall, Boca Raton, 1993.

Brodley, C. and Freidl, M.: Decision tree classification of land cover from remotely sensed data, Remote Sens. Environ., 61, 399-409, 1997.

Budyko, M.: Climate and Life, Academic, New York, 1974.
Burn, D. H.: Catchment similarity for regional flood frequency analysis using seasonality measures, J. Hydrol., 202, 212-230, doi:10.1016/s0022-1694(97)00068-1, 1997.

Burn, D. H. and Goel, N. K.: The formation of groups for regional flood frequency analysis, Hydrolog. Sci. J., 45, 97-112, doi:10.1080/02626660009492308, 2000.

Carrillo, G., Troch, P. A., Sivapalan, M., Wagener, T., Harman, C., and Sawicz, K.: Catchment classification: hydrological analysis of catchment behavior through process-based modeling along a climate gradient, Hydrol. Earth Syst. Sci., 15, 3411-3430, doi:10.5194/hess-15-3411-2011, 2011.

Cheng, L., Yaeger, M., Viglione, A., Coopersmith, E., Ye, S., and Sivapalan, M.: Exploring the physical controls of regional patterns of flow duration curves - Part 1: Insights from statistical analyses, Hydrol. Earth Syst. Sci., 16, 4435-4446, doi:10.5194/hess-16-4435-2012, 2012.

Dooge, J.: Looking for hydrologic laws, Water Resour. Res., 22, 46S-58S, 1986.

Duan, Q., Schaake, J., Andréassian, V., Franks, S., Goteti, G., Gupta, H., Gusev, Y., Habets, F., Hall, A., Hay, L., Hogue, T., Huang, M., Leavesley, G., Liang, X., Nasonova, O., Noilhan, J., Oudin, L., Sorooshian, S., Wagener, T., and Wood, E.: Model Parameter Estimation Experiment (MOPEX): An overview of science strategy and major results from the second and third workshops, J. Hydrol., 320, 3-17, 2006.

Haines, A. T., Finlayson, B. L., and McMahon, T. A.: A global classification of river Regimes, Appl. Geogr., 8, 255-272, 1988.

Köppen, W.: Das Geographisca System der Klimate, in: Handbuch der Klimatologie, edited by: Köppen, W. and Geiger, G., 1. C. Gebr., Borntraeger, 1-44, 1936.

Lailiberte, A., Fredrickson, E., and Rango, A.: Combining decision trees with hierarchical object-oriented image analysis for mapping arid rangelands, Photogramm. Eng. Rem. S., 73, 197-207, 2007.

Li, H., Sun, J., and Wu, J.: Predicting business failure using classification and regression tree: An empirical comparison with popular classical statistical methods and top classification mining methods, Expert Syst. Appl., 37, 5895-5904, 2010.

McDonnell, J. and Woods, R.: On the need for catchment classification, J. Hydrol., 299, 2-3, 2004.

Milly, P.: Climate, soil water storage, and the average water balance, Water Resour. Res., 30, 2143-2156, 1994.

Mosley, M. P.: Delimitation of New Zealand hydrologic regions, J. Hydrol., 49, 173-192, doi:10.1016/0022-1694(81)90211-0, 1981.

Ogunkoya, O. O.: Towards a delimitation of southwestern Nigeria into hydrological regions, J. Hydrol., 99, 165-177, doi:10.1016/0022-1694(88)90085-6, 1988.

Olden, J., Kennard, M., and Pusey, B.: A framework for hydrologic classification with a review of methodologies and applications in ecohydrology, Ecohydrology, 5, 503-518, 2012.

Peel, M. C., Finlayson, B. L., and McMahon, T. A.: Updated world map of the Köppen-Geiger climate classification, Hydrol. Earth Syst. Sci., 11, 1633-1644, doi:10.5194/hess-11-1633-2007, 2007

Pena-Barragan, J., Ngugi, M., Plant, R., and Six, J.: Object-based crop identification using multiple vegetation indices, textural features and crop phenology, Remote Sens. Environ., 115, 1301$1316,2011$. 
Quinlan, J.: Induction of Decision Trees, Mach. Learn., 1, 81-106, 1986.

Sawicz, K., Wagener, T., Sivapalan, M., Troch, P. A., and Carrillo, G.: Catchment classification: empirical analysis of hydrologic similarity based on catchment function in the eastern USA, Hydrol. Earth Syst. Sci., 15, 2895-2911, doi:10.5194/hess-15-28952011, 2011.

Sivapalan, M., Takeuchi, K., Franks, S., Gupta, V., Karambiri, H., Lakshmi, V., Liang, X., McDonnell, J., Menidiondo, E., O'Connell, P., Oki, T., Pomeroy, J., Schertzer, D., Uhlenbrook, S., and Zehe E.: IAHS decade on predictions in Ungauged Basins. (PUB), 2003-2012, Shaping an exciting future for the hydrological sciences, Hydrolog. Sci. J., 48, 857-880, 2003.

Sivapalan, M., Yaeger, M., Harman, C., Xu, X., and Troch, P.: Functional model of water balance variability at the catchment scale: 1. Evidence of hydrologic similarity and space-time symmetry, Water Resour. Res., 47, W02522, doi:10.1029/2010WR009568, 2011.

Wagener, T., Sivapalan, M., Troch, P., and Woods, R.: Catchment classification and hydrologic similarity, Geog. Comp., 1/4, 901931, 2007.
Walsh, R. and Lawler, D.: Rainfall seasonality: description, spatial patterns and change through time (British Isles, Africa), Weather, 36, 201-208, 1981.

Yaeger, M., Coopersmith, E., Ye, S., Cheng, L., Viglione, A., and Sivapalan, M.: Exploring the physical controls of regional patterns of flow duration curves - Part 4: A synthesis of empirical analysis, process modeling and catchment classification, Hydrol. Earth Syst. Sci., 16, 4483-4498, doi:10.5194/hess-16-44832012, 2012.

Ye, S., Yaeger, M., Coopersmith, E., Cheng, L., and Sivapalan, M.: Exploring the physical controls of regional patterns of flow duration curves - Part 2: Role of seasonality, the regime curve, and associated process controls, Hydrol. Earth Syst. Sci., 16, 44474465, doi:10.5194/hess-16-4447-2012, 2012.

Yokoo, Y. and Sivapalan, M.: Towards reconstruction of the flow duration curve: development of a conceptual framework with a physical basis, Hydrol. Earth Syst. Sci., 15, 2805-2819, doi:10.5194/hess-15-2805-2011, 2011.

Zhang, L., Dawes, W., and Walker, G.: Response of mean annual evapotranspiration to vegetation changes at catchment scale, Water Resour. Res., 37, 701-708, 2001. 